\section{Factors Influencing Flowering of Different South African Iridaceae}

\author{
Luise Ehrich ${ }^{\mathbf{1}, 2}$, Christian Ulrichs, and Heiner Grüneberg \\ Institute for Horticultural Sciences, Humboldt University of Berlin, \\ Germany, Lentzeallee 75, 14195 Berlin, Germany
}

Additional index words. Freesia, Sparaxis, Tritonia, inflorescence initiation, new floricultural crops

\begin{abstract}
Because South African Iridaceae have a high potential as new floricultural crops, four spring-flowering geophytic species originating in the Cape Floral Region were investigated. A total of 900 corms for each Freesia laxa, Sparaxis $\times$ tricolor, Tritonia deusta, and Tritonia securigera were exported from South Africa during dormancy in 2 subsequent years. Experiments in Berlin, Germany, focused on storage conditions after export and different temperature and light intensity regimes for forcing, in particular their effect on plant habit, inflorescence induction, and flowering success. The results showed that after export, dormancy could be further maintained in storage at temperatures above $20^{\circ} \mathrm{C}$. Temperature was found to be the main criterion to successfully realize flowering after planting; cultivation at $13{ }^{\circ} \mathrm{C}$ at night was essential with temperatures of $17^{\circ} \mathrm{C}$ and above possible during the day. During summer months, the failure of inflorescences in the terminal bud to develop completely, or the abortion of flower primordia within the corms, was the result of the high temperatures present. Also, low natural light levels during fall months could be linked to flower abortion of the investigated species. However, the results indicate that if forced as pot plants for the European fall and winter, the low temperature requirements of the investigated species during cultivation could represent substantial energy savings for future growers.
\end{abstract}

From the huge reservoir of potential new floricultural crops in the Cape Floral Region (CFR) of South Africa, its outstanding variety of geophytes, namely $16 \%$ of its total species (Van Wyk and Smith, 2001), forms a largely untouched plant group in horticulture. The Iridaceae, containing 27 genera and $\approx 700$ species in the CFR (Manning et al., 2002) _ among them the well-known genera Freesia and Gladiolus - are characterized by their diversity of flower colors (Niederwieser et al., 2002).

Freesia laxa (Thunberg) Goldblatt \& Manning, Sparaxis $\times$ tricolor, Tritonia deusta Ker Gawler, and Tritonia securigera Ker Gawler have a flower color range with mainly shades of orange, red, and pink. They were chosen for their potentially high ornamental value, but also for their commercial availability in sufficient numbers to conduct statistically adequate trials.

All four species/hybrids are winter-growing and spring-flowering in South Africa and 15 to $40 \mathrm{~cm}$ tall. They form corms that enable survival of the hot and dry summers during which they become dormant. The temperature drop and the onset of winter rains evoke their sprouting and vegetative growth, during which an inflorescence is formed by the shoot apical meristem (Manning et al., 2002).

Received for publication 22 Apr. 2009. Accepted for publication 21 July 2009.

${ }^{1}$ Current address: P.O. Box 12124, Garden Route Mall, George 6546, South Africa.

${ }^{2}$ To whom reprint requests should be addressed; e-mail luise_ehrich@hotmail.com. is therefore energy cost-saving during winter months compared with crops originating in the tropics.

To be able to force the chosen species/ hybrids as pot plants, detailed investigations on growth rhythms and growth requirements need to be undertaken to provide information on their physiology, especially the mechanisms of flower induction, and on how their cultivation can be regulated and optimized to eventually determine their potential as new pot plants (Dole, 2003; Rees, 1992). The findings of Ascough et al. (2006) for several species of Watsonia, also members of the Iridaceae and originating in South Africa, showed facultative or obligate vernalization requirements for successful flowering as well as an improved flowering percentage under long day conditions. Because of the limited information regarding the physiology and cultivation of the investigated species/hybrids, the chosen trial treatments were based on and compared with findings for the taxonomically related Freesia hybrids well known in cultivation. Results presented focus on the mechanisms of flower induction in the investigated species/hybrids and the influence of temperature and light intensity during that process.

\section{Materials and Methods}

The project was conducted in cooperation with New Plant Nursery, a wholesale nursery situated in George, South Africa, that provided the plant material. The corms of driedoff plants were harvested in Jan. 2005 and 2006 and stored at $20{ }^{\circ} \mathrm{C}$ and above at the nursery before air-freighting them to Europe in Apr. 2005 and 2006.

The investigations were executed in two sets of experiments. From the beginning of 2005 (planting April to June), preliminary experiments were carried out in the first trialing year to determine general growth requirements of the chosen species/hybrids. From the beginning of 2006, detailed investigations were carried out to determine the specific forcing requirements of the chosen species and hybrids in the second trialing year. After arrival in Germany, the corms were stored in climatic chambers at $22{ }^{\circ} \mathrm{C}$ (except for one treatment at $2{ }^{\circ} \mathrm{C}$ ). The corms were planted individually in $12-\mathrm{cm}$ pots in a medium composed of 2 peat-based medium: 1 perlite (volume). Liquid fertilization was carried out with Kristalon Weiss (Duelmen, Germany) (15N-2.2P-24.9K plus trace elements) at $2 \mathrm{~g} \cdot \mathrm{L}^{-1}$. Plant protection was necessary against thrips, spider mites, aphids as well as gnats and control obtained with various pesticides, e.g., Dimethoate (Bayer CropScience, Monheim am Rhein, Germany).

Two batches of corms were planted, one in May 2006 [spring batch (SB), corms stored at $22{ }^{\circ} \mathrm{C}$ (one treatment at $2{ }^{\circ} \mathrm{C}$ ) for 4.5 months in total before planting] and one in Sept. 2006 [fall batch (FB), corms stored at $22{ }^{\circ} \mathrm{C}$ (one treatment at $2{ }^{\circ} \mathrm{C}$ ) for 8.5 months in total before planting]. The following treatments were examined (all parameters including the number of corms planted are the same as for control unless otherwise stated):
- Treatment 1 (SB and FB): control [longterm storage at $22{ }^{\circ} \mathrm{C}$ and $65 \%$ relative humidity (RH), 3 weeks at $13{ }^{\circ} \mathrm{C}$ before planting, forcing at $17{ }^{\circ} \mathrm{C}$ day $/ 13{ }^{\circ} \mathrm{C}$ night under natural daylength and light intensity (automated shading in the greenhouses at greater than $1.3 \times 10^{6} \mu \mathrm{mol} \cdot \mathrm{m}^{-2} \cdot \mathrm{s}^{-1}$ in summer, automated energy screen opening at less than $3.7 \times 10^{4} \mu \mathrm{mol} \cdot \mathrm{m}^{-2} \cdot \mathrm{s}^{-1}$ in winter), weekly liquid fertilization, 50 corms planted per species].

- Treatment 2 (SB and FB): storage for 5 weeks at $5{ }^{\circ} \mathrm{C}$ before planting.

- Treatment 3 (SB and FB): storage for 6 weeks at $13{ }^{\circ} \mathrm{C}$ before planting.

- Treatment 4 (SB and FB): forcing at greater than $20^{\circ} \mathrm{C}, 35$ corms planted per species.

- Treatment 5 (SB and FB): forcing at $13{ }^{\circ} \mathrm{C}$ in climatic chamber with high-pressure 
metal halide lamps at $250 \mathrm{~W} \cdot \mathrm{h}^{-1}$ for $12 \mathrm{~h} \cdot \mathrm{d}^{-1}$ and $65 \%$ to $70 \% \mathrm{RH}$ from date of planting, 15 corms planted per species.

- Treatment 6 (FB): long-term storage at $2{ }^{\circ} \mathrm{C}$ (otherwise as control).

- Treatment 7 (FB): supplemental lighting at $400 \mathrm{~W} \cdot \mathrm{h}^{-1}$ with high-pressure sodium lamps for $12 \mathrm{~h} \cdot \mathrm{d}^{-1}$ from date of planting (otherwise as control).

Corms and plant development were regularly monitored by collecting the following data: height of plants in centimeters, starting date of anthesis, percentage of flowering plants for each species/treatment combination as well as number of inflorescences per plant and number of flower primordia per inflorescence. During the trials, flower initiation was determined by regular microscopic examination of the shoot apex of specimens of the different treatments during both years' trials with an optical microscope at a magnification of $\times 40, \times 100$, and $\times 200$ every 2 to 4 weeks. As a result of the sacrificial nature of these microscopic examinations, not more than one or two plants per treatment could be used for each investigation. The experiments with the single factor treatment were arranged in a completely randomized design with 15 (Treatment 5), 35 (Treatment 4), to 50 plants (depending on the sprouting success) per treatment for each species or hybrid. Statistical analysis of data through an analysis of variance as well as contingency tables was performed (where applicable) with the program Statgraphics Plus Version 4.1 for Windows.

\section{Results and Discussion}

The preliminary trials during 2005 indicated that the high temperatures prevailing during the hot European summer months (over $22{ }^{\circ} \mathrm{C}$ during the day almost daily for more than 2 months) led to high rates of inflorescence abortion. They could be determined after microscopic examination of the apical meristem showed successful flower induction, but only a few plants actually flowered.

Table 1 summarizes the duration from the planting date until flower initiation could be microscopically determined for the first time for each treatment of the investigated species/ hybrids during the spring and fall batches of the trials started in 2006. The different stages of inflorescence initiation were digitally photographed and two of them are illustrated for Freesia laxa as examples in Figures 1 and 2. The principal result of these microscopic investigations was that inflorescence formation in the terminal bud was temperature independent for Freesia laxa, Tritonia deusta, and Sparaxis $\times$ tricolor, and was also accomplished, although in tendency later, in the hot summer months of the spring batch (Table 1). Unfortunately, no statistical analysis could be applied to the data in Table 1 because the random sample size of one or two specimens per microscopic investigation was insufficient. However, the indicated results can be compared with the physiological reaction of Freesia hybrids for which $12{ }^{\circ} \mathrm{C}$ is optimal for flower initiation and differentiation. Higher average temperatures delay these processes (Imanishi, 1993). Only for Tritonia securigera was a cool temperature regime $\left[17{ }^{\circ} \mathrm{C}\right.$ day/ $13{ }^{\circ} \mathrm{C}$ night (FB) or continuous $13{ }^{\circ} \mathrm{C}$ (Treatment 5)] found to be compulsory for the formation of a floral meristem.

However, the trials in 2006-2007 also showed that continuous high temperatures after inflorescence formation in the apical meristem resulted in its abortion within the corm or shortly before emergence for all chosen species and hybrids as could also be detected for all investigated species/ hybrids during the microscopic examinations. Freesia laxa was the least sensitive in that regard with the highest percentage of flowering plants compared with the other investigated species/hybrids during the spring batch 2006 [values of up to $49 \%$ compared with values of only $0 \%$ to $33 \%$ (spring batch data not shown in Table 2)]. This reaction is also known for Freesia hybrids when subjected to high temperatures during the period of flower development (Imanishi, 1993). The highest percentage of flowering plants forced at continuous $13{ }^{\circ} \mathrm{C}$ ( $73 \%$ to $100 \%$ ) compared with the percentage of all other treatments (less than
$50 \%$ ) in the spring batch for all investigated species/hybrids furthermore suggests that cool temperatures play a more important role for successful flowering than (natural) long day conditions. The lower growing temperatures used for the fall batch led to a higher percentage of flowering plants of all investigated species and hybrids, as summarized in Table 2, and were essential to achieve optimal plant qualities (attractive foliage and a satisfactory number of flowering plants per treatment). Despite these positive effects, the naturally low light intensities of the nonirradiated treatments during the winter months of the fall batch also led to flower abortion or a delay in flowering of Sparaxis $\times$ tricolor and Tritonia securigera, but had no negative effect on Freesia laxa (Table 2). As a result of the mentioned sacrificial nature of the microscopic investigations of the corm, a precise number of initiated and later aborted inflorescences cannot be shown. However, it can be assumed that all plants of those treatments for which an inflorescence formation was microscopically detected, but later did not flower, did actually abort them.

This negative effect of low light intensities on flowering has also been described by Imanishi (1993) for Freesia hybrids. Unfortunately, the results of Ascough et al. (2006) regarding the lower flowering percentages of some Watsonia species under short day conditions does not include microscopic investigations of whether the inflorescences in those plants subjected to short day conditions were not formed at all, their development was delayed, or they were aborted as a result of short day conditions after formation. Nevertheless, negative effects of short days have also been reported by De Hertogh and Le Nard (1993) for the flowering of Sparaxis so that the possibility of a negative effect of short days in conjunction with low light intensities on the flowering success of the investigated species/hybrids cannot be excluded. This was shown for Gladiolus, another related genus of the Iridaceae, for which both short days and reduction of light intensity increase flower abortion (Halevy, 1975).

Table 1. Number of weeks from planting until first microscopic determination of floral meristem initiation of the treatments of Freesia laxa, Sparaxis $\times$ tricolor, Tritonia deusta, and Tritonia securigera realized in the spring and fall batches 2006-2007.

\begin{tabular}{|c|c|c|c|c|}
\hline \multicolumn{5}{|c|}{ Spring batch } \\
\hline Treatment & Freesia laxa & Sparaxis $\times$ tricolor & Tritonia deusta & Tritonia securigera \\
\hline 2 (preplanting storage at $5^{\circ} \mathrm{C}$ for 4 weeks) & 13 & 7 & 10 & - \\
\hline 3 (preplanting storage at $13^{\circ} \mathrm{C}$ for 6 weeks) & 13 & 7 & 4 & - \\
\hline 5 (forcing at continuous $13{ }^{\circ} \mathrm{C}$ ) & 13 & 7 & 10 & 7 \\
\hline \multicolumn{5}{|c|}{ Fall batch } \\
\hline Treatment & Freesia laxa & Sparaxis $\times$ tricolor & Tritonia deusta & Tritonia securigera \\
\hline 3 (preplanting storage at $13{ }^{\circ} \mathrm{C}$ for 6 weeks) & 9 & 6 & 6 & 14 \\
\hline 4 (forcing at continuous greater than $20^{\circ} \mathrm{C}$ ) & 17 & 12 & 14 & - \\
\hline 5 (forcing at continuous $13^{\circ} \mathrm{C}$ ) & 9 & 9 & 9 & 9 \\
\hline 6 (preplanting storage at $2^{\circ} \mathrm{C}$ for 3.5 months) & 6 & 6 & 6 & 9 \\
\hline 7 (supplemental lighting at $\left.400 \mathrm{~W} \cdot \mathrm{h}^{-1}\right)$ & 14 & 6 & 6 & 12 \\
\hline
\end{tabular}




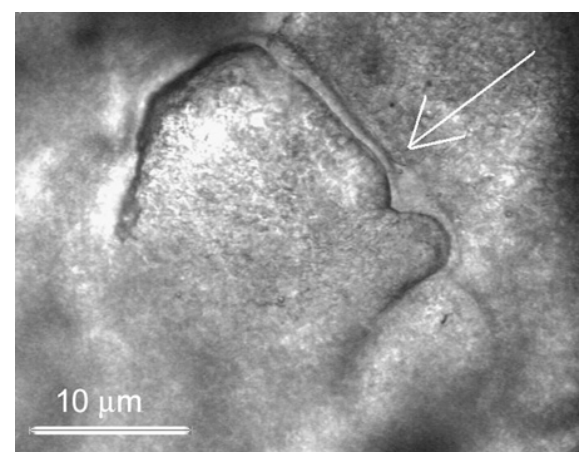

Fig. 1. Stage Pr-Br of inflorescence initiation in Freesia laxa. The bract primordium is formed opposite the last leaf and another primodium initiated in its axil (arrow). Standard abbreviations for the stages of inflorescence initiation in flower bulbs according to De Hertogh and Le Nard (1993): $\mathrm{Pr}=$ first flower primordia visible; $\mathrm{Br}=$ flowers bearing bracts, specialized leaves; $\mathrm{P}_{1}=$ first whorl of perianth; $\mathrm{P}_{2}=$ second whorl of perianth.

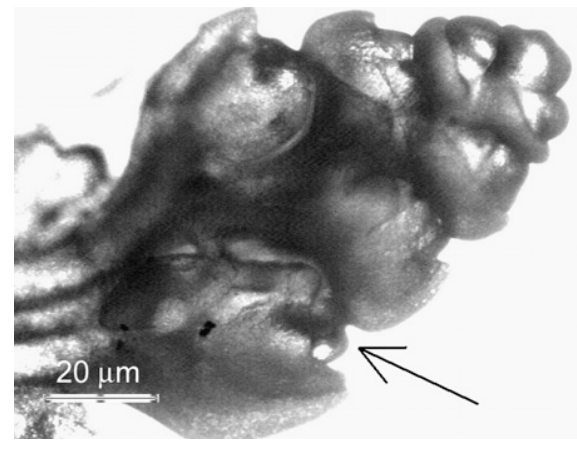

Fig. 2. Stage $\mathrm{P}_{1}-\mathrm{P}_{2}$ of inflorescence initiation in Freesia laxa. The perianth primodia develop (arrow). Standard abbreviations for the stages of inflorescence initiation in flower bulbs according to De Hertogh and Le Nard (1993): $\mathrm{Pr}=$ first flower primordia visible $\mathrm{Br}=$ flowers bearing bracts, specialized leaves; $\mathrm{P}_{1}=$ first whorl of perianth; $\mathrm{P}_{2}=$ second whorl of perianth.
The preplanting storage of the corms for 4 weeks at $5{ }^{\circ} \mathrm{C}$ (Treatment 2) had no significant beneficial effects on advancing the anthesis date of all investigated species and hybrids compared with the control (Table 2) and to the findings of Wulster et al. (1989) for pot freesias. The statistically significant reduction in plant height of pot freesias achieved by Berghoef and Zevenbergen (1990) by an extended storage at $13{ }^{\circ} \mathrm{C}$ before planting (Treatment 3) was confirmed for Freesia laxa during the spring batch (reduction by $5.46 \mathrm{~cm}$, test of Nemenyi with $\alpha=$ $5 \%$ ), in which it also increased the percentage of flowering plants compared with the control ( $45 \%$ compared with $13 \%$ in the spring batch and a statistically significant difference as shown in Table 2 in the fall batch). For Tritonia deusta, this treatment lead to a 6week earlier inflorescence formation in the apex meristem compared with the control (Table 1) and to a 3-week advanced anthesis, although only $11 \%$ (significantly less than the control) of these plants flowered (Table 2). These effects were probably the result of the growing conditions favoring flower abortion after inflorescence formation. Plant quality of Sparaxis $\times$ tricolor and Tritonia securigera was greatly reduced by subjecting the corms to a longer storage at $13{ }^{\circ} \mathrm{C}$ before planting, because this treatment led to irregular and poor growth.

Plants grown at a continuous $20{ }^{\circ} \mathrm{C}$ or above (Treatment 4 ) in the spring and fall batches demonstrated that cultivation at these temperatures led to a delay or inhibition of flowering for all investigated species/hybrids (Tables 1 and 2), confirming what the 2005 trials had already indicated. Plants of Treatment 5 grown in the climatic chamber at a continuous $13{ }^{\circ} \mathrm{C}$ displayed $70 \%$ to $100 \%$ flowering in both batches of all species/ hybrids. However, the number of inflorescences as well as the number of flower primordia per inflorescence of Treatment 5 plants was generally lower than those of Treatment 7 plants grown under supplemen- tal lighting (data not shown). For all species/ hybrids except Freesia laxa, these plants of Treatment 5 had the significantly highest flowering percentage in the fall batch compared with all other treatments realized except the plants grown under supplemental lighting of Treatment 7.

The long-term storage at $2{ }^{\circ} \mathrm{C}$ was carried out after the corms of all species and hybrids had already undergone a 3- to 4-month warm storage in South Africa, and so this temperature treatment cannot be fully compared with the cold storage carried out commercially for freesia hybrid corms directly after harvest and before the high temperature treatment as described by Imanishi (1993). After planting, the effect of the storage at $2{ }^{\circ} \mathrm{C}$ differed among the chosen species and hybrids. A portion of the corms subjected to the $2{ }^{\circ} \mathrm{C}$ storage (Treatment 6 ) of Tritonia deusta $(48 \%)$ and Sparaxis $\times$ tricolor $(60 \%)$ pupated after planting, an unexpected result. This physiological phenomenon is known in freesias and denotes a process in which the original corm is replaced by a daughter corm without any aerial vegetative growth, the new corm also being dormant. The remaining corms sprouted and grew very poorly. Comparably, the plants of the same treatment of Tritonia securigera displayed a dissatisfactory, i.e., less vigorous, growth compared with the control plants, although no pupation was observed. In comparison, the reaction to the cold storage of Freesia laxa was most surprising. The plants whose corms were subjected to a $2{ }^{\circ} \mathrm{C}$ storage before planting formed inflorescences 6 weeks earlier (Table 1), anthesis was advanced by 8 weeks (Table 2), and there was a significant increase in the number of inflorescences per plant compared with control plants (2.71 compared with 1.67 inflorescences per plant, Mann-Whitney test with $\alpha=5 \%$ ). Furthermore, significantly higher flowering was achieved among the Treatment 6 plants of this species compared with all other treatments except Treatment 5 (Table 2).

Table 2. Percentage of flowering plants (\%) from calendar Week 48 (2006) to calendar Week 7 (2007) of the treatments of Freesia laxa, Sparaxis $\times$ tricolor, Tritonia deusta, and Tritonia securigera realized in the fall batch.

\begin{tabular}{|c|c|c|c|c|c|c|c|c|c|c|}
\hline \multirow[b]{2}{*}{ Treatment } & \multicolumn{5}{|c|}{ Freesia laxa } & \multicolumn{5}{|c|}{ Sparaxis $\times$ tricolor } \\
\hline & Week 48 & 51 & 03 & $07^{\mathrm{z}}$ & $\mathrm{N}$ in week 07 & 48 & 51 & 03 & 07 & $\mathrm{~N}$ in week 07 \\
\hline 1 (control) & 0 & 0 & 0 & $43 \mathrm{~b}$ & 28 & 0 & 5 & 13 & $13 \mathrm{a}$ & 40 \\
\hline 2 (preplanting storage at $5{ }^{\circ} \mathrm{C}$ for 4 weeks) & 0 & 0 & 4 & $46 \mathrm{bc}$ & 28 & 0 & 0 & 0 & $3 \mathrm{a}$ & 39 \\
\hline 3 (preplanting storage at $13{ }^{\circ} \mathrm{C}$ for 6 weeks) & 0 & 0 & 6 & $74 \mathrm{~d}$ & 31 & 0 & 0 & 0 & $0 \mathrm{a}$ & 37 \\
\hline 4 (forcing at continuous greater than $20^{\circ} \mathrm{C}$ ) & 0 & 0 & 0 & $5 \mathrm{a}$ & 19 & 0 & 0 & 0 & $0 \mathrm{a}$ & 22 \\
\hline 5 (forcing at continuous $13^{\circ} \mathrm{C}$ ) & 0 & 0 & 0 & 82 cde & 11 & 0 & 8 & 75 & $75 \mathrm{~b}$ & 12 \\
\hline 6 (preplanting storage at $2{ }^{\circ} \mathrm{C}$ for 3.5 months) & 3 & 50 & 76 & 94 e & 33 & 0 & 8 & 8 & $8 \mathrm{a}$ & 12 \\
\hline \multirow[t]{2}{*}{7 (supplemental lighting at $\left.400 \mathrm{~W} \cdot \mathrm{h}^{-1}\right)$} & 0 & 0 & 3 & $50 \mathrm{bc}$ & 36 & 2 & 32 & 72 & $93 \mathrm{~b}$ & 43 \\
\hline & \multicolumn{5}{|c|}{ Tritonia deusta } & \multicolumn{5}{|c|}{ Tritonia securigera } \\
\hline Treatment & Week 48 & 51 & 03 & 07 & $\mathrm{~N}$ in week 07 & $\overline{48}$ & 51 & 03 & 07 & $\mathrm{~N}$ in week 07 \\
\hline 1 (control) & 0 & 0 & 5 & $34 \mathrm{~b}$ & 44 & 0 & 0 & 0 & $3 \mathrm{a}$ & 34 \\
\hline 2 (preplanting storage at $5^{\circ} \mathrm{C}$ for 4 weeks) & 0 & 0 & 9 & $30 \mathrm{~b}$ & 44 & 0 & 0 & 0 & $0 \mathrm{a}$ & 38 \\
\hline 3 (preplanting storage at $13{ }^{\circ} \mathrm{C}$ for 6 weeks) & 0 & 0 & 9 & $11 \mathrm{a}$ & 45 & 0 & 0 & 0 & $0 \mathrm{a}$ & 42 \\
\hline 4 (forcing at continuous greater than $20^{\circ} \mathrm{C}$ ) & 0 & 0 & 0 & $20 \mathrm{ab}$ & 25 & 0 & 0 & 0 & $0 \mathrm{a}$ & 29 \\
\hline 5 (forcing at continuous $13^{\circ} \mathrm{C}$ ) & 0 & 0 & 54 & $92 \mathrm{c}$ & 13 & 0 & 0 & 33 & $100 \mathrm{~b}$ & 0 \\
\hline 6 (preplanting storage at $2{ }^{\circ} \mathrm{C}$ for 3.5 months) & 0 & 33 & 45 & $45 \mathrm{~b}$ & 20 & 0 & 0 & 0 & $0 \mathrm{a}$ & 43 \\
\hline $7\left(\right.$ supplemental lighting at $\left.400 \mathrm{~W} \cdot \mathrm{h}^{-1}\right)$ & 0 & 0 & 17 & $74 \mathrm{c}$ & 47 & 0 & 0 & 0 & $83 \mathrm{~b}$ & 7 \\
\hline
\end{tabular}

${ }^{\mathrm{z}}$ Data of calendar Week 7 was subjected to the $\chi^{2}$ test for homogeneity for contingency tables. Any two percentages of each species not followed by the same letter are significantly different in pairwise comparisons with $\alpha=5 \%$. 


\section{Conclusion}

The trials from 2005 to early 2007 showed that the export of dormant corms of all the investigated species/hybrids was uncomplicated and that their dormancy could be further maintained by storing the corms at either 2 or $22{ }^{\circ} \mathrm{C}$. Subsequently, the species/ hybrids reacted differently when subjected to various forcing regimes, especially regarding the number of weeks until a floral meristem could be microscopically detected and the percentage of flowering plants within the batches. Despite these differences, the growth factors temperature, but also light intensity played a central role for the successful vegetative, but predominantly generative stage of the plants, i.e., the flowering success. Although high temperatures (greater than $20{ }^{\circ} \mathrm{C}$ ) during growth could only prevent the formation of a floral meristem in one of the four investigated species (Tritonia securigera), they led to a partial or almost total abortion of inflorescences before emergence. Furthermore, low natural light intensities and short days during European fall months also led to inflorescence abortion for all investigated species/hybrids except Freesia laxa. For successful inflorescence induction and subsequent anthesis, the species/hybrids should be grown at temperatures under $20{ }^{\circ} \mathrm{C}$ with $13{ }^{\circ} \mathrm{C}$ at night to secure successful inflorescence induction and anthesis. Although the different physiological reactions of the investigated species/hybrids were similar to those of Freesia hybrids, some of them have to be individually determined for each new species, e.g., their sensitivity to low light intensities and short day conditions. It is hoped that the results presented will increase the interest in South African geophytes, especially regarding their potential as new floricultural crops as well as their potential energy savings for future growers as a result of their low temperature requirements during cultivation.

\section{Literature Cited}

Ascough, G.D., N.P. Mtshali, D.I. Thompson, N.O. Anderson, J.E. Erwin, and J. van Staden. 2006. Watsonia, p. 599-605. In: Teixera da Silva, J.A. (ed.). Floriculture, ornamental and plant biotechnology. Vol. IV. Global Science Books, Isleworth, UK.

Berghoef, J. and A.P. Zevenbergen. 1990. The effect of precooling environmental factors and growth-regulating substances on plant height of Freesia as a pot plant. Acta Hort. 266:251257.
De Hertogh, A.A. and M. Le Nard (eds.). 1993. The physiology of flower bulbs. Elsevier, Amsterdam, The Netherlands.

Dole, J.M. 2003. Research approaches for determining cold requirements for forcing and flowering of geophytes. HortScience 38:341-346.

Halevy, A.H. 1975. Light energy flux and distribution of assimilates as factors controlling the flowering of flower crops. Proc. 19th International Horticultural Congress (1974). 4:125134.

Imanishi, H. 1993. Freesia, p. 285-296. In: De Hertogh, A.A. and M. Le Nard (eds.). The physiology of flower bulbs. Elsevier, Amsterdam, The Netherlands.

Manning, J.C., P. Goldblatt, and D. Snijman. 2002. The color encyclopedia of Cape bulbs. Timber Press, Portland, OR.

Niederwieser, J.G., R. Kleynhans, and F.L. Hancke. 2002. Development of a new flower bulb crop in South Africa. Acta Hort. 570:67-73.

Rees, A.R. 1992. Ornamental bulbs, corms and tubers. CAB Publishing International, Wallingford, UK.

Van Wyk, A.E. and G.F. Smith. 2001. Regions of floristic endemism in Southern Africa. Umdaus Press, Hatfield, South Africa.

Wulster, G.J., S. Cartwright, and T.J. Gianfagna. 1989. The effects of greenhouse temperature and ancymidol concentration on height and flowering time of Freesia hybrida grown as container plant. Acta Hort. 252:97-103. 